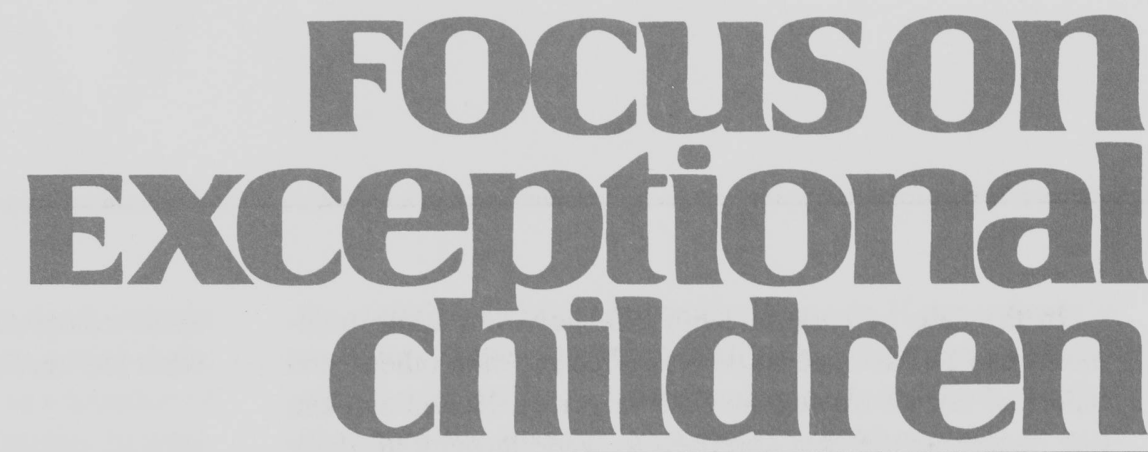

\title{
Searching for the Best Model for Instructing Students With Learning Disabilities
}

\section{H. Lee Swanson}

Students with learning disabilities (LD) comprise a heterogeneous group so no general instructional model can be recommended for all of them. Thus, the title of this article might seem to be somewhat of a misnomer. Nevertheless, some common general principles for teaching students with LD can be assumed to exist. Effective interventions include some instructional components that capitalize on these principles. Although these principles often operate in different ways with different students, in different content areas, and in different settings, they can be used in designing effective remediation programs for LD students.

In this article, findings are summarized related to a comprehensive educational intervention research synthesis for students with learning disabilities (Swanson, Hoskyn, \& Lee, 1999) that attempts to identify the principles underlying effective instruction. Although there have been several technical reports related to this synthesis (e.g., Swanson, 1999; Swanson \& Hoskyn, 1998; Swanson \& Sachse-Lee, 2000), the purpose of this article is to consider more directly the practical aspects of the findings. More specifically, the focus will be on the question: What instructional components or activities characterize highly effective intervention programs for students with LD?

On the surface, identifying key instructional components that improve LD students' performance might seem to be a relatively simple, although time-consuming, task. One could simply take all the studies published in refereed journals that yield positive outcomes for students with LD and then summarize the instructional principles that make up those studies. In fact, most syntheses that attempt to translate research to practice rely on such procedures. Such an approach is problematic, however, because the published literature is biased toward reporting positive treatment outcomes (e.g., Begg, 1994).

A quick perusal of the published literature reveals a plethora of published treatments (i.e., bona fide instructional models) reflecting a diversity of approaches that yield positive outcomes for students with LD. Such a state of affairs has been called a "Dodo bird" effect (e.g., Lubrosky, Singer, \& Luborsky, 1975). Taken from a conclusion of the Dodo bird in Alice in Wonderland (Carroll, 1965/1962), the bird stated, "Everybody has won, and all must have prizes" (p. 412). Unquestionably, this effect is disconcerting when attempting to search for some general principles of effective instruction.

Dr. Swanson is a professor of Educational Psychology and Special Education at the University of California, Riverside. 
In the case of children with LD, however, some treatments can be assumed to be less effective than others, and therefore not all treatments deserve prizes. How, then, can one determine the best approach to wade through all these studies that yield positive outcomes? One approach allowing comparison of the treatments that yield positive outcomes for students with LD is to place studies on the same level playing field. This is done by equating studies by their methodological sophistication (to be discussed later). If this is not done, the race as depicted in Alice in Wonderland becomes haphazard:

\footnotetext{
[The competitors] were placed along the course, here and there. There was no "One, two, three and away," but they began running when they liked, and left off when they liked so that it was not easy to know when the race was over. (p. 45)
}

Thus, the assumption is made that if studies are put on an equal footing methodologically speaking with control for publication biases by including nonpublished studies in our synthesis, we can identify some common components that make for a generally effective instructional model. Before detailing attempts to sort through the literature to identify

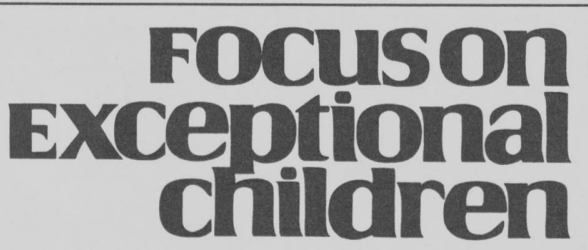

ISSN 0015-511X FOCUS ON EXCEPTIONAL CHILDREN (USPS 203-360) is published monthly except June, July, and August as a service to teachers, special educators, curriculum specialists, administrators, and those concerned with the special education of exceptional children. This publication is annotated and indexed by the ERIC Clearinghouse on Handicapped and Gifted children for publication in the monthly Current Index to Journals in Education (CIJE) and the quarterly index, Exceptional Children Education Resources (ECER). The full text of Focus on Exceptional Children is also available in the electronic versions of the Education Index. It is also available in microfilm from Xerox University Microfilms, Ann Arbor, MI. Subscription rates: Individual, \$36 per year; institutions, $\$ 48$ per year. Copyright (C) 2001, Love Publishing Company. All rights reserved. Reproduction in whole or part withou written permission is prohibited. Printed in the United States of America. Periodical postage is paid at Denver, Colorado. POSTMASTER: Send address changes to:

$$
\begin{gathered}
\text { Love Publishing Company } \\
\text { Executive and Editorial Office } \\
\text { P.O. Box } 22353 \\
\text { Denver, Colorado } 80222 \\
\text { Telephone (303) } 221-7333
\end{gathered}
$$

\begin{tabular}{cc}
$\begin{array}{c}\text { Karen Harris } \\
\text { University of Maryland }\end{array}$ & $\begin{array}{c}\text { Thomas Skrtic } \\
\text { University of Kansa }\end{array}$ \\
\multicolumn{2}{c}{$\begin{array}{c}\text { James Shriner } \\
\text { University of Illinois }\end{array}$} \\
Erica J. Lawrence & $\begin{array}{c}\text { Stanley F. Love } \\
\text { Editor }\end{array}$ \\
Publisher
\end{tabular}

those components, however, we would do well to review what has been found in previous syntheses of the literature.

\section{PREVIOUS SYNTHESES}

Reviews of the instructional literature that have been influential in providing an understanding of treatment outcomes for students with LD use a procedure called metaanalysis (e.g., Kavale \& Forness, 2000; Mastropieri, Scruggs, Bakken, \& Whedon, 1996). Meta-analysis is a statistical reviewing technique that provides a quantitative summary of findings across an entire body of research (Cooper \& Hedges, 1994). The results of individual studies are converted to a standardized metric or effect size. The scores then are aggregated across the sample of studies to yield an overall estimate of effect size. Particular attention is given to the magnitude of the effect size estimate. According to Cohen (1988), .80 is considered a large effect size estimate, .50 a moderate estimate, and .20 a small estimate.

There have been several excellent meta-analyses on instructional research in learning disabilities (e.g., Kavale \& Forness, 2000, Mastropieri et al., 1996), but none to our knowledge has considered intervention research across a broad array of academic domains and/or controlled for variations in methodology. The only synthesis to my knowledge that provided an overall estimate of treatment effectiveness prior to the present synthesis was our own previous synthesis (Swanson, Carson \& Lee, 1996). A collection was assembled of published group-designed studies (78) between 1967 and 1993, which focused on youth 6-18 years of age; and reported from a total of 324 effect sizes a mean effect size of .85 for treatment versus control conditions. Using Cohen's (1988) threshold of .80 for large effects, the earlier meta-analysis suggested that various instructional approaches have had a significant beneficial effect when used with children and adolescents who have learning disabilities.

Two important findings come out of this earlier synthesis. First, in contrast to the Dodo bird effect, our earlier synthesis suggested that not all forms of intervention work equally well. In this synthesis, studies were classified into one of four general instructional orientations: therapeutic (eclectic), remedial, direct instruction, or cognitive strategies. The classification was determined by the hypothesis of the study, as well as key words in the introduction, abstract, and title of each article related to the treatment of choice. Mean effect size scores were .59 for the eclectic approaches (approaches not directed specifically to academic skills), .91 for direct instruction, .68 for remedial instruction, and 1.07 for strategy instruction. Thus, a higher effect size emerged for direct and strategy instruction when compared to the other approaches. 
Second, no particular academic or behavioral domain (e.g., reading, mathematics, spelling, language, social skills, memory, cognition) was resistant to change as a function of intervention. Although most of the research related to intervention was in the reading domain (reading comprehension, word recognition), no differences in effect sizes were found across targeted domains (processing, social skills, mathematics, spelling).

In summary, we must point out that, although this previous analysis found some advantages for direct and strategy instruction, other general models also produced high effect sizes. One reason for this may have been that the earlier synthesis relied on categorizing the intervention approaches by how the primary author labeled the experimental condition rather than by coding the actual procedures and components of instruction used in the study.

The former approach is problematic for several reasons, the most obvious being that treatments shared many of the same instructional activities (e.g., corrective feedback, active participation of the learner, teaching skill in a cumulative manner). Therefore, the distinction between various treatments was more artificial than real.

\section{SEPARATING STUDIES INTO STRATEGY AND DIRECT-INSTRUCTION MODELS}

To address this flaw in the earlier synthesis, studies in this new synthesis were sorted by components represented in the treatment studies. Thus, studies were divided along lines in terms of those that reflect strategies and those that emphasize direct instruction. Before discussing how the studies were sorted as reflecting either direct or strategy instruction in the current synthesis, we emphasize the distinctions and overlap between the two general instructional approaches. Readers have to keep in mind that the distinctions are sometimes subtle, which creates difficulties in clearly analyzing the two approaches.

Consider the following study in our synthesis that contrasts both approaches: Lovett et al. (1994) compare both strategy and direct instruction intervention models on wordrecognition outcomes. Both approaches include a graduated sequence of steps with multiple opportunities for overlearning the content and skills in a reading program. Both instructional models include cumulative review routines, mass practice, and teaching of all component skills to mastery criterion.

For the strategy model, the students learn sound units with additional discussion given to metacognitive issues such as strategy implementation, strategy choice, and selfmonitoring. Clear discussion is given to students about (a) why a strategy facilitates word recognition, (b) how to apply the strategy, and (c) how to check to see if the strategy is working. Students systematically practice these strategies with target words. A compare-and-contrast activity explicitly trains the students on what they need to know to help them decode a new word.

The direct instruction condition follows the same procedures as strategy instruction except for two variations:

1. Direct instruction focuses on subskills (sound units, such as letter sounds, or linguistic units, such as matcat-hat).

2. Discussion of processes and use of general rules is minimized.

Thus, what seems to separate the two instructional models is focus. The strategy program focuses on processes or global skills for a general approach to reading, whereas a direct instruction model focuses on word segmentation and "sound-getting skills." A further contrast between the two models is that the strategy model calls for teaching a few words to mastery, whereas the direct instruction model concentrates on a level of subanalysis or segmentation (phonological awareness).

Although direct and strategy instruction treatments may be distinguished by the unit of information (i.e., direct instruction focuses primarily on isolated skills, whereas strategy instruction focuses primarily on rules) and processing perspective (direct instruction is characterized as a bottom-up processing approach and strategy instruction as a top-down processing approach), other distinctions are less subtle. For example, components of direct instruction were reviewed by Engelmann and Carnine (1982), Kameenui, Jitendra, \& Darch (1995), Rosenshine (1995), and Slavin, Karweit, and Madden (1989). These reviews show that direct instruction emphasizes fast-paced, well sequenced, and highly focused lessons. The lessons usually are taught in small groups of students who are given several opportunities to respond and receive feedback about accuracy and responses (See Kameenui et al., 1995, for a review of model variations).

Components related to effective strategy instructional programs also are reviewed elsewhere (see Borkowski \& Turner, 1990; Levin, 1986; Pressley \& Ghatala, 1990; Sternberg, 1998; Swanson, 1993). These components include:

- advanced organizers (providing students with a type of mental scaffolding on which to build new understanding)

- organization (directing students to stop from time to time to assess their understanding)

- elaboration (thinking about the material to be learned in a way that connects the material to information or ideas already in their mind) 
- generative learning (making sense of what they are learning by summarizing the information)

- general study strategies (underlining, note taking, summarizing, having student generated questions, outlining, and working in pairs to summarize sections of materials)

- thinking about and controlling one's thinking process (metacognition)

- attributions (evaluating the effectiveness of a strategy).

Given the distinctions between the two models, how do they overlap? An answer to this question is important because it may account for some of the confusion in differentiating the two models. Strategy instruction and direct instruction models overlap in at least two ways. First, both models (in one form or another) assume that effective methods of instruction include (a) daily reviews, (b) statements of an instructional objective, (c) teacher presentation of new material, (d) guided practice, (e) independent practice, and (f) formative evaluations (see Rosenshine, 1995; Rosenshine \& Stevens, 1986; Shuell, 1996; Slavin, Stevens, \& Madden, 1988, for a review). Second, both direct instruction and strategy instruction follow a sequence of events, such as the following:

1. State the learning objectives and orient the students to what they will be learning and what performance will be expected of them.

2. Review the skills necessary to understand the concept.

3. Present the information, give examples, and demonstrate the concepts/ materials.

4. Pose questions (probes) to students and assess their level of understanding and correct misconceptions.

5. Provide group instruction and independent practice. Give students an opportunity to demonstrate new skills and learn the new information on their own.

6. Assess performance and provide feedback. Review the independent work and give a quiz. Give feedback for correct answers and reteach skills if answers are incorrect.

7. Provide distributed practice and review.

No doubt the above sequence has variations within a strategy or direct instruction model (e.g., Graham \& Harris, 1996; Lovett et al., 1994).

In summary, the instructional components that make up the two orientations have points of distinction as well as commonality. The present synthesis compares outcomes of studies that included these various components. Because of the tremendous overlap in components, however, we drew upon general literature reviews for comparative purposes to operationalize the models.
Specifically, treatments were coded as reflecting direct instruction if four of the following criteria were present:

1. Breaking down a task into small steps

2. Administering probes

3. Administering feedback repeatedly

4. Providing a pictorial or diagram presentation

5. Allowing for independent practice and individually paced instruction

6. Breaking the instruction down into simpler phases

7. Instructing in a small group

8. Teacher modeling a skill

9. Providing set materials at a rapid pace

10. Providing individual child instruction

11. Teacher asking questions

12. Teacher presenting the new (novel) materials.

Studies were categorized as strategy instruction if they included at least three of the following instructional components:

1. Elaborate explanations (systematic explanations, elaborations, and/or plan to direct task performance)

2. Modeling from teachers (verbal modeling, questioning, and demonstration from teachers)

3. Reminders to use certain strategies or procedures (cues to use taught strategies, tactics, or procedures)

4. Step-by-step prompts or multi-process instructions

5. Dialogue (teacher and student talk back and forth)

6. Teacher asks questions

7. Teacher provides only necessary assistance.

Based on the operational criteria, some studies could be expected to share both strategy instruction and direct instruction criteria. Therefore, studies were separated further into those that included only strategy components (SIonly model), those that included only direct-instruction components (DI-only), those that included both strategy and direct instruction components (combined model; i.e., includes a minimum of three strategy and four directinstruction components), and studies that did not include the minimum number of components for either direct or strategy instruction (nondirect instruction and nonstrategy instruction model). Thus, the latter studies may have included some components of either model, but none of these studies met a critical threshold of strategy or direct instruction components.

[Note: To some, the classification of studies as direct or strategy instruction by meeting a minimum threshold of components may seem arbitrary. A comparison of studies, however, which listed more components than others (these were referred to as high-saturation studies), did not yield a difference in the pattern of results. Further, "minimum threshold" 
studies, because of page constraints, may have listed only the most important components and therefore were included to ensure that the findings were not biased by the studies that reported the treatment in greater detail.]

\section{PROCEDURES IN SEARCHING AND CLASSIFYING THE LITERATURE}

Consideration has been given to issues related to identifying effective instructional models before discussing the results of the most recent meta-analysis. At this point, we will review procedures used to assess the relevant literature, along with information related to three questions: (1) How were the studies selected for analysis?, (2) How were the instructional treatments categorized?, and (3) How were instructional components categorized?

How did we come up with the studies for analysis? The search procedures are described in detail in Swanson and Hoskyn (1998) and, therefore, are summarized here. The PsycINFO, MEDline, and ERIC on-line data bases were systematically scanned for studies from 1963 to 1997 that met the inclusion criteria described below. The computer search strategy used the following terms: "learning disabled (disabilities)," or "reading disabled (disabilities)," or "dyslexic," or "educationally handicapped," or "slow learners," paired with variations of "intervention" or "treatment" or "training" or "remediation" or "instruction." This search yielded approximately 2,900 abstracts including articles, technical reports, chapters, and dissertations. Because the computer search procedures excluded unpublished studies and the most recent literature, researchers (as identified by journal board affiliations with the Learning Disability Quarterly, Journal of Learning Disabilities, and Learning Disabilities Research and Practice and/or membership in the International Academy for Research in Learning Disabilities) were sent letters requesting copies of unpublished and/or ongoing intervention studies.

The pool of relevant literature was narrowed to studies that used an experimental design in which children or adults with LD received treatment to enhance their academic, social, and/or cognitive performance. This procedure narrowed the search to 913 data-based articles (or reports) that seemed to be potentially acceptable for including in the quantitative review. After a review of these studies, each data-based report was evaluated on five additional criteria for study inclusion.

1. The study had at least one between-instruction comparison (i.e., control condition) or within-design control condition (e.g., repeated measures design) that includes participants with LD.
2. The study provided sufficient quantitative information to permit the calculation of effect sizes.

3. Recipients of the intervention were children or adults with average intelligence who had problems in a specific academic, social, and/or related behavior domain.

4. The treatment group received instruction, assistance, or therapy over and above what they would have received during the course of their typical classroom experience. That is, the study focused on treatment rather than merely a description of the child's current placement followed by an evaluation.

5. The study had to be written in English.

Although design issues (e.g., no control condition) constituted the most frequent reason for excluding an article, other frequent reasons for excluding articles were the inability to calculate effect sizes, lack of clarity about whether students with LD were included, the inability to separate the performance of students with LD from other ability groups, no information on sample size, and/or faulty statistical applications (e.g., incorrect degrees of freedom).

How did we categorize the treatment variables? Based on the criteria provided in the introduction, studies to be classified fell into one of four models: strategy + direct instruction (referred to as the combined model), direct instruction (DI-alone), strategy instruction (SI-alone) and the nondirect + nonstrategy instruction model (nondirect instruction and nonstrategy instruction, i.e., studies that failed to reach a critical threshold of "reported" information). As a validity check on these classifications, classification of the treatment conditions was compared to that of the primary authors' general theoretical model and/or the label attached to the treatment condition. There was substantial overlap (approximately $70 \%$ of the studies) between the studies we classified ascombined, DI-alone, and SI-alone models with the primary authors' titles or description of the independent variables.

For example, frequent terms provided by the author were: "strategy," "cognitive intervention," "monitoring," "metacognition," "self-instruction," and "cognitive-behavior modification" for the strategy model. Those that were classified as DI by the present criteria used labels such as: "directed instruction," "advanced organizers," "adapting materials," or "corrective feedback" or "direct computation." Approaches that were below the component threshold (they did not include the minimum number of components required for being labeled as either direct instruction or strategy intervention) used, for example, labels such as "reinforcement-only," "modeling-only," or "social skills training." 
How did we categorize instructional components? There were 45 instructional activities that were coded as present or not present in the study (see the Appendix to this article). Based on comprehensive reviews that have identified instructional components that influenced student outcomes (e.g., Brophy \& Good, 1986; Leinhardt \& Greeno, 1986; Pressley \& Harris, 1994; Rosenshine, 1995; Shuell, 1996; Sternberg, 1998), we reclustered (or reconfigured) the 45 instructional activities shown in Appendix A into 18 clusters of components for later analysis.

We coded the occurrence of the following instructional components (also provided are the numbers related to the coding sheet provided in the Appendix):

1. Sequencing. Statements in the treatment description related to breaking down the task, and/or sequencing short activities (activity numbers 12 and 29).

2. Explicit practice. Statements in the treatment description related to distributed review and practice, repeated practice, sequenced reviews, daily feedback, and/or weekly reviews (activity numbers 23, $26,27,39$, and 45).

3. Novelty. Statements in the treatment description about which a new curriculum was implemented, and/or emphasis on teacher presenting new material from the previous lesson (activity numbers 20 and 38).

4. Attributions. Statements in the treatment description about the teacher presenting the benefits of taught strategies (activity 41).

5. Reinforcement. Statements in the treatment description about intermittent or consistent use of rewards and reinforcers (activity 28).

6. Peer modeling. Statements in the treatment description about model peers presenting or modeling instruction (activity 18).

7. Task reduction. Statements in the treatment description about breaking down the targeted skill into smaller units, mastery criteria, and/or task analysis (activity nos. 1, 17, and 34)).

8. Advanced organizers. Statements in the treatment description about directing children to look over material prior to instruction, children directed to focus on particular information, providing prior information about task, and/or the teacher stating objectives of instruction (activities 2, 3, 11, and 40).

9. Questioning. Treatment description related to directing students to ask questions, the teacher and student or students engaging in dialogue, and/or the teacher asking questions (activities 33, 35, and 36).

10. One-to-one instruction. Statements in the treatment description about activities related to independent practice, tutoring, instruction that is individually paced, and/or instruction that is individually tailored (activities 9, 10, and 13).

11. Control difficulty or processing demands of a task. Treatment statements about probing learning, fading probes or prompts, short activities so the level of difficulty is controlled, and/or teacher providing necessary assistance (activities 4, 7, 16, and 42).

12. Technology. Statements in the treatment description about developing pictorial representations, using specific material or computers, and/or using media to facilitate presentation and feedback (activities 5, 31, and 44).

13. Elaboration. Statements in the treatment description about additional information or explanation provided about concepts, and/or redundant text or repetition within text (activities 6, 24, and 30).

14. Skill modeling. Statements or activities in the treatment descriptions that involve modeling from teacher in terms of skills (activity 19).

15. Small-group Instruction. Statements in the treatment description about instruction in a small group, and/or verbal interaction occurring in a small group with students and/or teacher (activity 14).

16. A supplement to teacher involvement. Statements in the treatment description about homework and/or parents helping reinforce instruction (activities 8, 21, and 22).

17. Strategy cues. Statements in the treatment description about reminders to use strategies or multi-steps, the teacher verbalizing steps or procedures to solve problems, and/or use of "think aloud models" (activities 25,32 , and 43 ).

18. Large-group learning. Statements in the treatment description about instruction in large groups and/or teacher-only demonstration (activities 15 and 37).

The components associated most often with strategy instruction programs are best reflected in component numbers $4,8,9,11,13,15$, and 17. For example, the advanced organizer component (no. 8) characterizes treatment approaches that activate prior knowledge or provide a precursor to the main instructional activity (e.g., Meichenbaum's [1977] cognitive-behavioral model). The component that reflected the Control of difficulty or processing demands of a task addressed the variations in teacher support of the student (e.g., the teacher provided necessary assistance, tasks sequenced from easy to difficult, i.e., help was provided to the student that covaries with the learner's ability) and reflected activities such as mediated scaffolding (e.g., Palincsar \& Brown, 1984). Following an explicit set of steps and prompting the use of these steps (strategy cue) are 
considered to be important activities that underlie strategy instruction (Rosenshine, 1995).

Although all studies included in the present synthesis met all of selection criteria, this does not mean that the studies were of equal methodological sophistication. Just because a study has a control condition, it does not follow that methodological problems have been controlled. To address this issue, we coded each study on a number of methodological variables and created methodological composite scores related to both internal validity and methodological sophistication. Studies were assigned a positive score on the following methodological dimensions:

1. Instructional sessions greater than 10 (selection of this variable was based on the assumption that the intensity of instruction as reflected by the number of sessions yields more reliable and stable outcomes than shorter intervention sessions)

2. Random assignment to treatment

3. Multiple measures of treatment integrity (treatment was carried out as intended)

4. Use of standardized tests (higher reliability than experimental measures)

5. Internal validity scores of 11 [number reflects the best possible ratings on items-see above]

6. Score assigned to overlapping high control and treatment condition in terms of steps and procedures (at least three steps and/or procedures overlap).

The amount of standardized test information reported was included in the methodological composite score [if additional psychometric information beyond an IQ score was reported (e.g., reading scores)]. For each study, the composite score across the seven variables varied from 14 to 0 , with 14 reflecting methodologically superior studies. The mean methodological composite score for the 180 studies was 7.25 , suggesting that, on an average, studies fell in the middle of the present methodological continuum.

\section{TYPICAL CHARACTERISTICS OF STUDIES IN THIS SYNTHESIS}

The analyses yielded 180 group design studies, which encompassed approximately 1,600 effect sizes comparing students with LD in the experimental condition with students with LD in the control condition. The mean effect size, which takes into consideration the sample size across the 180 studies was .65 . An average intervention study included 23 minutes of daily instruction, three times a week, over 36 days. The mean sample size for the study was 27 . The mean treatment age was 11 years.
Materials for the experimental conditions were commercial (33\% of the studies), novel (materials developed by the researcher, $54 \%$ of the studies), or a combination of commercial and novel ( $9 \%$ of the studies), or were not classifiable (4\% of the studies). The most frequent commercial materials $(N=54)$ were related to direct instruction (e.g., Corrective Reading, Distar, SRA, 8\%), Houghton Mifflin series (4\%), Orton-Gillingham approach (4\%), and Lindamood-Bell (4\%). In terms of student activities during treatment, 30 of the studies had participants monitor or evaluate (via recording, counting, charting, checking, graphing, and/or verbalizing) their academic behavior.

\section{A THREE-TIER STRATEGY FOR ANALYZING THE STUDIES}

After the general characteristics of the studies had been analyzed, we analyzed the studies in terms of instructional approaches. We used a three-tier structure to investigate the various instructional approaches. For the first tier, four general intervention models were compared. As stated previously, the four general models were DI-alone (direct instruction components, but below a threshold of strategy components), SI-alone (strategy components, but below a threshold of DI components), direct instruction coupled with strategy instruction (combined model, which included both strategy and direct instruction components), and studies that did not meet the threshold for classification as either direct instruction or strategy instruction (referred to as the nondirect instruction and nonstrategy instruction model).

The four models yielded significantly different mean effect sizes when the methodological composite scores and the age of the sample were partialed from the analysis. The mean effect sizes and the total number of studies $(\mathrm{N})$ were $.84(N=55), .68(N=47) .72(N=28)$, and $.62(N=43)$ for the combined, DI-alone, SI-alone, and nondirect instruction and nonstrategy instruction models, respectively. A followup test indicated that the combined model yielded significantly higher effect sizes than the other models (combined $>$ $\mathrm{DI}$ alone $=\mathrm{SI}$ alone $=$ nondirect instruction and nonstrategy instruction).

What do these findings suggest? Although the combined model superseded the other models, the magnitude of the effect sizes for all four general approaches is high. These high effects emerged even when the analysis took into account methodological and age variations between studies. Thus, support is found for the aforementioned Dodo bird effect. This finding was a little disconcerting because it seems to suggest that no matter what the intervention, academic behavior always improves. Perhaps a more optimistic way of looking at these findings is to conclude that these studies are tapping some common components. 
To address this question, Table 1 shows the percent of studies that included each of the 18 components. More than $40 \%$ of all the studies included instructional components related to sequencing, task reduction, one-to-one instruction, and technology. Infrequently reported instructional components were related to attribution training, direct reinforcement, elaboration, and supplements to teacher instruction.

The analysis also determined whether studies that yielded high effect sizes as well as high methodological scores were more likely to use specific instructional components. Columns 2 and 3 in Table 1 show studies that achieved a high methods composite score ( $>7$ with 14 as the highest) but yielded effect sizes at or above .60 and those below .60 , respectively. These comparisons indicate that no one instructional component was reported in more than $40 \%$ of the studies.

The component in which $30 \%$ of the studies were represented was one-to-one instruction. For the high methodshigh effect size studies, no instructional components except

\section{TABLE 1}

\section{Percent of Instructional Components Reported in Studies}

\begin{tabular}{lrrc} 
& Total & $\begin{array}{c}\text { High } \\
\text { Methods } \\
\text { High Effect } \\
\text { Sizes }\end{array}$ & $\begin{array}{c}\text { High } \\
\text { Methods } \\
\text { Low Effect } \\
\text { Sizes }\end{array}$ \\
\hline 1. Sequencing & 46.7 & 21.84 & 25.29 \\
2. Explicit practice & 32.8 & 19.54 & 11.49 \\
3. Novelty & 39.4 & 18.39 & 19.54 \\
4. Attributions & 1.0 & - & - \\
5. Reinforcement & 6.1 & 1.15 & 2.30 \\
6. Peer modeling & 3.3 & 1.15 & 5.75 \\
7. Task reduction & 41.1 & 22.99 & 24.14 \\
8. Advanced & & & \\
organizer & 28.3 & 10.34 & 10.34 \\
9. Questioning & 15.0 & 4.60 & 17.02 \\
10. One-to-one & & & \\
instruction & 68.3 & 29.89 & 40.23 \\
11. Control difficulty & 38.9 & 21.84 & 19.54 \\
12. Technology & 50.0 & 21.84 & 22.89 \\
13. Elaboration & 5.0 & 1.15 & 0 \\
14. Skill modeling & 26.1 & 8.05 & 14.84 \\
15. Small-group & & & \\
instruction & 22.8 & 13.79 & 19.15 \\
16. Supplemental & & & \\
instruction & 6.1 & 4.60 & 1.15 \\
17. Strategy cues & 19.4 & 11.49 & 8.90 \\
18. Large-group & & & \\
learning & 38.3 & 16.09 & 21.84 \\
\hline
\end{tabular}

the one-to-one component was above $25 \%$. For the high methods-low effect size studies, components that approached the $25 \%$ representation were sequencing (component no. 1) and task reduction (component no. 7).

The difficulty with the present analysis is that instruction seldom represents a single component but, instead, interacts with other components in treatment outcomes. That is, instructional components seldom act independently in the context of other components. For example, no teacher merely focuses on sequencing or strategy instruction without taking into consideration whether instruction should be one-to-one, small-group, or some combination of these settings. Thus, the next analysis identified those instructional components, when coupled with other components, that best predict effect size. Before this can occur, however, it is necessary to determine components that seem to co-occur with other components in studies.

It was assumed that components that frequently co-occur reflect a common factor. What are those factors? To determine the instructional components that shared a common factor (cluster together), an exploratory factor analysis was done.

As shown in Table 2, the analysis yielded an eight-factor solution. Complete details of this analysis are found in Swanson (in press). To simplify the table, an $\mathrm{X}$ is placed beside the component that loads (correlates) with a particular factor (i.e., a component with a factor loading greater than .39).

What do you think these eight factors represent? As shown in Table 2, the first factor loads highly on instructional components related sequencing, reducing task demands, advanced organizers, and the modeling of skills. Factor 1 clearly reflects the sequencing and segmentation of information. This factor was labeled as explicit direct instruction because such a model emphasizes that the steps of instruction are presented in an explicit sequential fashion (e.g., Lovett et al., 1994).

The second factor loads high on explicit practice, strategy cuing, and elaboration. The second factor was interpreted as reflecting direct and explicit strategy training. This factor is characteristic of some of the components found in models outlined by several authors (e.g., Borkowski, Weyhing, \& Carr, 1988; Graham \& Harris, 1989; Miller \& Seier, 1994; Pressley, Brown, El-Dinary, \& Allferbach, 1995). The steps include a description of the strategy, modeling its use, verbal rehearsal of steps, guided practice and feedback with material/or teacher instruction that elaborates information.

The third factor loads on components related to implementing new curriculum, advance organizers, and controlling the difficulty of item presentation. Because the components reflect the monitoring of new information, this 


\section{TABLE 2 \\ Factor Analysis of Components}

\begin{tabular}{|c|c|c|c|c|c|c|c|c|}
\hline \multirow[b]{2}{*}{ Variable } & \multicolumn{8}{|c|}{ Factors } \\
\hline & 1 & 2 & 3 & 4 & 5 & 6 & 7 & 8 \\
\hline 1. Sequencing & $X X$ & & & & & & & \\
\hline 2. Explicit practice & & $X X$ & & $X X$ & & & & \\
\hline 3. Novelty & & & $X X$ & & & & & \\
\hline 4. Attributions & & & & & & & $x X$ & \\
\hline 5. Reinforcement & & & & $x x$ & & & & \\
\hline 6. Peer modeling & & & & & & $x X$ & & \\
\hline 7. Task reduction & $x X$ & & & & & & & \\
\hline 8. Advanced organizer & $x x$ & & $X X$ & & & & & \\
\hline 9. Questioning & & & & & & & $x X$ & \\
\hline 10. One-to-one instruction & & & & $x X$ & & & & \\
\hline 11. Control difficulty & & & $X X$ & $x x$ & & & & \\
\hline 12. Technology & & & & & & & & $x X$ \\
\hline 13. Elaboration & & $X X$ & & & & & & \\
\hline 14. Skill modeling & $x X$ & & & & & & $x X$ & \\
\hline 15. Small-group instruction & & & & & $x X$ & & & \\
\hline 16. Supplemental instruction & & $X X$ & & & & & & \\
\hline 17. Strategy cues & & $X X$ & & & & & & \\
\hline 18. Large-group learning & & & & & $x X$ & & & \\
\hline
\end{tabular}

component is referred to as instructional monitoring. Monitoring is emphasized in programs such as cognitive behavior modification (Meichenbaum, 1977).

The fourth factor loads highly on one-to-one instruction and reinforcement. Because these activities are associated with several skills-training programs (e.g., Lovett et al., 1994; Vellutino \& Scanlon, 1991), this factor was labeled as individualized remedial instruction.

As with factor 4, factor 5 reflects a setting variable. Factor 5 contrasts the large-group setting with a small-group setting. This factor was referred to as small interactive group instruction.

Factor 6 loads highly on components related to peer modeling and ancillary activities (homework, parent help). This factor was referred to as a teacher-indirect instruction, and therefore we view this factor as ancillary or supplemental to direct or explicit instruction.

Factor 7 loads on the components related to attribution training as well as instruction that includes verbal questioning/dialogue and skill modeling. This factor includes components characteristic of several strategy models that rely on verbal mediation (e.g., Borkowski et al., 1988; Palincsar, 1986). This factor was referred to as verbal questioning/ attribution instruction.
Factor 8 loads highly on the medium of instruction. These mediums focus on computer presentations, strategy flow charts, and the like. This factor was referred to as technology or media moderated instruction. This is in contrast to factor 7 , which focused directly on verbal dialogue as a mediation tool.

In sum, the instructional components can be boiled down to eight factors. Some of these seem to be clearly related to strategy components (e.g., factor 2, factor 7), whereas others are related to setting (factor 5) and still others to sequencing (factor 1).

Which factors contribute significantly to improving the magnitude of treatment outcomes? Although sorting the components that go together into factors made some empirical and practical sense, a question not addressed was which of the factors significantly improved the magnitude of the effect size. No doubt, an answer to this question is at the heart of this article. Thus, the next analysis summarized the results in more detail. The analysis used a special form of hierarchical regression analysis (see Hedge, 1994, for discussion). The eight factor scores, the methodological weighting of each study, and the age of the participants were used to predict the magnitude of treatment outcomes. The results are shown in Table 3. 
TABLE 3

Instructional Models for Predicting Effect Sizes

$\mathrm{R}^{2} \quad$ Increment $\mathrm{R}^{2}$

$\mathrm{R}^{2}$

Increment $\mathrm{R}^{2}$

Model 1

1. Methods

2. Age

Model 3

1. Strategy Instruction

2. Methods

3. Age

Model 5

1. Individual Remediation

2. Methods

3. Age

Model 7

1. Indirect

2. Methods

3. Age

Model 9

1. Technology

2. Method

3. Age

$\begin{array}{ll}.06^{\star} & - \\ .06 & -\end{array}$

$.07^{\star}$

$.10^{\star}$

.10

.03

-

.00

$.06^{*}$

.06

- 06

-

Model 2

1. Direct Instruction

2. Methods

3. Age

.01

$.07^{\star}$

.07

Model 4

1. Monitor

2. Methods

3. Age

Model 6

1. Small-Group

$.02^{*}$

2. Methods

3. Age

$.07^{\star}$

.07

Model 8

1. Attribution

.005

2. Methods

3. Age

$.06^{*}$

.06

Model 10

1. Direct Instruction

2. Small-Group

.01

$.03^{\star}$

3. Strategy Instruction

$.08^{\star}$

4. Methods

5. Age

$.12^{*}$

.12

Model 12

Model 11

1. Small-Group

$.02 *$

.03

$.08^{*}$

$.12^{\star}$

.12

5. Age

Model 13

1. Strategy Instruction

2. Direct Instruction

3. Small-Group

4. Methods

5. Age
1. Strategy Instruction

2. Small-Group

3. Direct Instruction

4. Methods

5. Age

Model 14

1. Small-Group

2. Strategy Instruction

3. Methods

4. Age
- 06

$-$

Direct Instruction = explicit direct instruction model

Strategy Instruction = explicit strategy instruction model Individual Remediation = individual remedial instruction model

Small-Group = small group interactive instruction model 
The cumulative percentage of variance $\left(\mathrm{R}^{2}\right)$ associated with the addition of variables is presented in the first and third columns. An asterisk (*) is placed beside the $\mathrm{R}^{2}$ if the factors significantly contributed to effect size. The increment in percentage associated with additional variables appears in the second and fourth columns.

Because the order of entry of these factors is known to influence the outcomes of regression analyses, several models were tested. To be precise, the amount of variance in effect size accounted for by (a) methods and age alone (model 1), and (b) methods and age after each factor score (model 2-9) was partialed out (controlled) was determined. Of interest was whether the contribution of methods and age to effect size was mediated by instructional components. As shown for the explicit strategy instruction (model 3), the factor score contributed significant variance to the magnitude of effect size. The results also indicated that small/ interactive instructional groups (model 6) contributed significant variance and reduced the contribution of the methods and age variables to effect size.

The largest contributor to effect size ( $7 \%$ of the variance) was explicit strategy instruction (model 3). Inspection of Table 3 also indicated that the total amount of variance related to the methods and age variable in predicting effect size was $6 \%$ (model 1). Following the addition of explicit strategy instruction (factor 2) in model 3, the contribution wàs reduced to $3 \%$. The drop in variance seems to account for $50 \%$ of the methodological/age-related variance in effect size [i.e., (.06-.03)/.06].

Will predictions of effect size be enhanced if direct instruction, explicit strategy instruction, and small-group instruction (factors 1, 2 and 5) are included in the predictions of effect size? The question was answered by varying the order of entry to determine if the factor scores contributed unique variance. As shown in Model 10, the contribution of direct instruction (factor 1) was not significant.

In contrast, Models 11 and 14 showed that small-group interactions (factor 5) contributed significant variance to effect size when entered before explicit strategy instruction (factor 2). Models 12 and 13, however, showed that explicit strategy instruction (factor 2) partialed out (i.e., the effect is no longer significant) the influence of small-group instruction (factor 5).

Thus, the results showed that Model 14 was the most parsimonious model because it removes the contribution of direct instruction (factor 1). The reduction in the methods/age variable in Model 14, however, was no better than that reported in Model 3.

In summary, Model 3, which included explicit strategy instruction (factor 2) provided the most parsimonious instructional model. This model also reduced the variance related to methods and age in predicting effect size. The multiple components model that yields the largest percentage of variance accounted for (largest $\mathrm{R}^{2}$ ) included explicit strategy instruction (factor 2) and small-group instruction (factor 5). The reader has to remember that these factors reflect high loadings (see Table 2) for instructional components related to explicit practice, elaboration, strategy cues, and small-group instruction.

\section{WHAT'S THE BIG PICTURE?}

What can be concluded from this synthesis when we talk about a general model of instruction for students with LD? There are three important findings related to improving the academic performance of students with LD.

First, an effective general model of instruction combining the components of direct and strategy instruction supersedes other models for remediating learning disabilities. More specifically, the effects size $(M=.84)$ of the combined strategy instruction and direct instruction model meets Cohen's (1988) criterion of .80 for a substantial finding. What are the instructional implications of this finding?

Over the years the literature has presented some lively debate about whether instruction should be top-down, via emphasizing the knowledge base, heuristics, and explicit strategies, or a bottom-up emphasis entailing hierarchical instruction at the skill level (e.g., Palincsar \& Brown, 1984; Vellutino \& Scanlon, 1991). In this synthesis, the combined model was contrasted with one approach (DI-only) considered as a bottom-up model and the other (SI-only) considered as a top-down model. The results show that combinations of specific components that reflect both of these orientations enhance yield higher outcomes. Based on the magnitude of the effect sizes for the DI and SI models (.68 for DI-only and .72 for SI-only) in isolation, both approaches seem viable for students with learning disabilities. Nevertheless, these approaches were smaller than the combined model in the magnitude of effect sizes.

Based on these findings, we conclude that effective instruction is neither a bottom-up nor a top-down approach in isolation. Lower-order and higher-order skills interact to influence treatment outcomes. Clearly, performance at complex levels (writing prose, inferring the meaning of text) cannot occur without some critical threshold of skills. Children with LD vary in these skills. What is clear from this synthesis, however, is that varying degrees of success across treatment domains draw from treatments that focus on both high- and low-order instruction (i.e., strategy and direct instruction).

Second, eight major instructional factors captured most intervention programs for students with LD. These factors were referred to as explicit direct instruction (sequencing 
and segmentation), explicit strategy training, monitoring, individualized remedial training, small interactive group instruction, teacher-indirect instruction, verbal questioning/ attribution instruction, and technology-mediated instruction.

As will be discussed below, however, not all of these factors predict (i.e., significantly improve) treatment outcomes. The coding of various components that loaded on the various factors was based on a thorough investigation of the literature. Several of these reviews have narrowed down effective instruction to the following: (a) daily reviews, (b) statements of an instructional objective, (c) teacher presentation of new material, (d) guided practice, (e) independent practice, and (f) formative evaluations (see Rosenshine, 1995; Rosenshine, \& Stevens, 1986; Slavin et al. 1988, for a review). These categories have been considered as reflecting a basic effective instructional core (Rosenshine \& Stevens, 1986; Slavin, Stevens, \& Madden, 1988). The components in the present synthesis that matched these basic instructional core practices are: explicit practice (component 2 ), orientation to a task (component 8), presentation of new material (component 6), teacher modeling of steps (component 14 ), sequencing (component 1 ), and systematic probing (component 5).

What the factor analysis shows is that all these components, except one, reinforcement, load on the first two factors in the present analysis. These factors reflect explicit direct instruction and explicit strategy instruction. In addition, both models contribute significant variance to the magnitude of effect size. The results also show that an additional factor, small interactive group instruction, not mentioned in this basic instructional core, significantly improves treatment outcomes.

Finally, the explicit strategy instruction factor better predicts the magnitude of treatment outcomes than any of the other competing factor models. As discussed previously, explicit strategy instruction has three instructional components. One component is explicit practice. Studies that include this component in their treatment programs focus on activities that relate to distributed review and practice, repeated practice, sequenced reviews, daily feedback, and/or weekly reviews.

Another component of this factor is strategy cues. Studies that include this component have statements in the treatment description about reminders to use strategies or multisteps, the teacher verbalizing steps or procedures to solve problems, and use of "think aloud models." The final component is elaboration. Studies that include this component have statements in their treatment description about additional information or explanation provided about concepts, and/or redundant text or repetition within text.

One interesting finding was that the factor score related to explicit strategy instruction was more important than a direct instruction model in predicting outcomes. That is, the explicit strategy instruction score partials out the influence of the direct instruction composite score in predicting the magnitude of treatment outcome. Clearly, performance at complex levels (writing prose, inferring the meaning of text) cannot occur without some critical threshold of skills delivered by direct instruction techniques. Children with learning disabilities vary in these skills. What is clear from this synthesis, however, is that varying degrees of success across treatment domains draw from treatments that include strategy instruction.

Because direct instruction and strategy instruction are complex combinations of components, however, we would not argue from these results that strategy instruction has better support than direct instruction for treatment outcomes. This is because strategy instruction program and direct instruction have many commonalities. Both approaches involve the active presentation of information, clear organization, step-by-step progression from subtopic to subtopic, use of many examples, demonstrations, and visual prompts. All emphasize conscious assessment of student understanding and altering the pace of instruction according to this information. The focus is on independent performance. Instruction is criterion-based rather than time-based. A stage is mastered before moving onto the next stage.

Clearly, however, there are differences in focus. As stated in the introduction, strategy interventions focus on routines and planful action and/or general principles of handling information, whereas direct instruction focuses on isolated skill acquisition to support higher-order processing. Nevertheless, much of the teaching in both approaches is explicit, relying on oral presentation by the teacher and oral responses by the students.

Thus, although direct instruction has been associated with the behavioral paradigms, cognitive paradigms use some of the same procedures. This point is illustrated by Swanson (1988), who suggests that, in practice, both cognitive and behavioral models use many of the same procedures (e.g., feedback, monitoring, repetition).

In summary, the results show that not all treatments win a prize. Which treatment wins the prize is based upon the level of analysis. At a general level, it appears that a combined direct and strategy instruction model is critical, whereas at the component level it appears that components that load on the explicit strategy and small-group factor are the most important in predicting outcomes.

Keeping these findings in mind, we think there is potential for making significant advances in devising programs for LD students if these components are included in the remediation program. We also think we will have a better chance of determining more robust treatments for LD students if both control and treatment conditions include these 
components. In this way, the unique aspects of the novel treatment program can be assessed more adequately. There are, of course, qualifications to the present findings. We will conclude with two of these shortcomings.

\section{SOME SHORTCOMINGS}

One qualification is that, although studies in this synthesis were selected on rigorous criteria, these studies varied tremendously on a number of methodological variables. The results clearly showed that the methodology composite scores moderated that magnitude of effect sizes. Specifically, five of the eight models based on the factor analysis contributed no significant variance to treatment outcome when the methodological composite score was entered into the analysis. These instructional models were related to models that emphasized monitoring of new information, individualized remedial instruction, ancillary teacher models (peer instruction, homework), attribution instruction, and those emphasizing media or technology.

Further, the age of students with LD did not play an important role in predicting the influence of the instructional variables. Thus, the results show that, for participants with LD across diverse samples, classroom settings, ages, and types of measures (e.g., reading, math, writing) only three factors or models moderate the magnitude of effect size.

The second qualification is related to the coding of instructional components. Although the coding of instructional activities was based on reviews of instructional literature, no attempt was made to code the treatment by what aspect of instruction was addressed (e.g., phonological awareness, inferential comprehension), but instead the present synthesis focused on how it was taught. Emphasis was placed on "how" the treatments were delivered because one cannot adequately assess the "what" of instruction unless the "how" is clearly identified. As shown by a previous synthesis (Swanson \& Hoskyn, 1998), there are tremendous differences in instructional activities, as well as a host of other methodological variables, that improve treatment outcomes. Unless instructional activities are identified and their influence on outcomes is clearly delineated, testing the subtle aspects of content becomes a moot point.

In conclusion, the results of this synthesis show that only a few instructional components significantly improve treatment outcomes for students with LD. The synthesis indicates that explicit strategy instruction and small-group instruction provide a valid model for improving outcomes for students with LD across a broad array of samples, settings, and dependent measures. Our hope is that these components will be a part of all intervention programs in the future.

\section{REFERENCES}

Begg, C. B. (1994). Publication bias. In H. Cooper \& L. V. Hedges (Eds.), The handbook of research synthesis (pp. 400-422). New York: Russell Sage Foundation.

Borkowski, J. G., Estrada, M. T., Milstead, M., \& Hale, C. A. (1989). General problem-solving skills: Relations between metacognition and strategic processing. Learning Disability Quarterly, 12, 57-70.

Borkowski, J. G., \& Turner, L. A. (1990). Transsituational characteristics of metacognition. In W. Schneider \& F. E. Weinert (Eds.), Interactions among aptitudes, strategies, and knowledge in cognitive performance (pp. 159-176). New York: Springer-Verlag.

Borkowski, J. G., Weyhing, R. S., \& Carr, M. (1988). Effects of attributional retraining on strategy-based reading comprehension in learningdisabled students. Journal of Educational Psychology, 80, 46-53.

Brophy, J., \& Good, T. (1986). Teacher-effects results. In M. C. Wittrock (Ed.), Handbook of research on teaching ( $3 \mathrm{~d}$ ed.). New York: Macmillan.

Carroll, L. (1962). Alice's adventure in wonderland. Harmondsworth, Middlesex, England: Penguin Books. (Original work published 1865)

Cohen, J. (1988). Statistical power analysis for the behavioral sciences, (2d ed.) New York: Academic Press.

Cooper, H. \& Hedges, L. (1994). (Eds.) The handbook of research synthesis. New York: Sage.

Engelmann, S., \& Carnine, D. W. (1982). Theory of instruction: Principles and applications. New York: Irvington.

Graham, S., \& Harris, K. R. (1989). A components analysis of cognitive strategy instruction: Effects on learning disabled students' compositions and self-efficacy. Journal of Educational Psychology, 81, 353-361.

Graham, S., \& Harris, K. R. (1996). Self-regulation and strategy instruction for students who find writing and learning challenging. In C. M. Levy \& S. Ransdell (Eds.), The science of writing: Theories, methods, individual differences, and applications (pp. 347-360). Mahwah, NJ: Lawrence Erlbaum Associates.

Hedges, L. V. (1994). Fixed effects models. In H. Cooper \& L. V. Hedges (Eds.), The handbook of research synthesis (pp. 285-299). New York: Russell Sage Foundation.

Kameenui, E. J., Jitendra, A. K., \& Darch, C. B. (1995). Direct instruction reading as contronym and eonomine. Reading \& Writing Quarterly: Overcoming Learning Difficulties, 11, 3-17.

Kavale, K. A., \& Forness, S. R. (2000). Policy decisions in special education: The role of meta-analysis. In R. Gersten, E. P. Schiller, \& S. Vaughn (Eds.), Contemporary special education research (pp. 281-326). Mahwah, NJ: Erlbaum.

Leinhardt, G., \& Greeno, J. G. (1986). The cognitive skill of teaching. Journal of Educational Psychology, 78(2), 75-95.

Levin, J. R. (1986). Four cognitive principles of learning strategy instruction. Educational psychologist, 21, 3-17.

Lovett, M. W., Borden, S. L., DeLuca, T., Lacerenza, L., Benson, N. J., \& Brackstone, D. (1994). Treating the core deficits of developmental dyslexia: Evidence of transfer of learning after phonologically and strategy-based reading training programs. Developmental Psychology, $30,805-822$.

Luborsky, L., Singer, B., \& Luborsky, L. (1975). Comparative studies of psychotherapies: Is it true that "everyone has won and all must have prizes”? Archives of General Psychiatry, 32, 995-1008.

Mastropieri, M. A., Scruggs, T. E., Bakken, J. P., \& Whedon, C. (1996). Reading comprehension: A synthesis of research in learning disabilities. In T. E. Scruggs \& M. A. Mastropieri (Eds.). Advances in learning and behavioral disabilities (Vol. 10, pp. 277-303). Greenwich, CT: JAI.

Meichenbaum, D. (1977). Cognitive behavior modification. New York: Plenum. 
Miller, P. H., \& Seier, W. L. (1994). Strategy utilization deficiencies in children: When, where and why. In H. W. Reese (Ed.), Advances in Child Development and Behavior (vol. 25, pp. 107-156). New York: Academic Press.

Palincsar, A. S. (1986). The role of dialogue in providing scaffolded instruction. Educational Psychologist, $21(1 \& 2), 73-98$.

Palincsar, A. S., \& Brown, A. L. (1984). Reciprocal teaching of comprehension-fostering and comprehension monitoring activities. Cognition \& Instruction, 1, 117-175.

Pressley, M., Brown, R., El-Dinary, P. B., \& Allferbach, P. (1995). The comprehension instruction that students need: Instruction fostering constructively responsive reading. Learning Disabilities Research \& Practice, 10(4), 215-224.

Pressley, M., \& Ghatala, E. S. (1990). Self-regulated learning: Monitoring learning from text. Educational Psychologist, 25, 19-34.

Pressley, M., \& Harris, K. R. (1994). Increasing the quality of educational intervention research. Educational Psychology Review, 6, 191-208.

Rosenshine, B. (1995). Advances in research on instruction. Journal of Educational Research, 88(5), 262-268.

Rosenshine, B., \& Stevens, R. (1986). Teaching functions. In M. C. Wittrock (Ed.), Handbook of research on teaching (3d ed.). New York: Macmillan.

Shuell, T. (1996). Teaching and learning in a classroom context. In D. Berliner \& R. C. Calfee (Eds.), Handbook of educational psychology (pp. 726-764). New York: Simon \& Schuster/Macmillan.

Slavin, R. E., Karweit, N. L., \& Madden, N. A. (1989). Effective programs for students at risk. Needham Heights, MA: Allyn \& Bacon.

Slavin, R. E., Stevens, R. J., \& Madden, N. A. (1988). Accommodating student diversity in reading and writing instruction: A cooperative learning approach. Special Issue: The challenge of reading with understanding in the intermediate grades: RASE: Remedial \& Special Education, 9(1), 60-66.

Sternberg, R. (1998). Principles of teaching successful intelligence. Educational Psychologist, 33, 65-72.

Swanson, H. L. (1988). Toward a metatheory of learning disabilities. Journal of Learning Disabilities, 21, 196-209.

Swanson, H. L. (1993). Principles and procedures in strategy use. In L. Meltzer (Ed.), Strategy assessment and instruction for students with learning disabilities: From theory to practice (pp. 61-92). Austin: ProEd.

Swanson, H. L. (1999). Instructional components that predict treatment outcomes for students with learning disabilities: Support for a combined strategy and direct instruction model. Learning Disabilities Research \& Practice, 14, 129-140.
Swanson, H. L. (in press). In search of the best strategy instruction model. Educational Psychology:

Swanson, H. L., Carson, C., \& Sachse-Lee, C. M. (1996). A selective synthesis of intervention research for students with learning disabilities. School Psychology Review, 25, 370-391.

Swanson, H.L., \& Hoskyn, M. (1998). A synthesis of experimental intervention literature for students with learning disabilities: A meta-analysis of treatment outcomes. Review of Educational Research, 68, 277-322.

Swanson, H. L. \& Sachse-Lee, C. M. (2000). A meta-analysis of singlesubject-design intervention research for students with LD. Journal of Learning Disabilities, 33, 114-136.

Swanson, H. L., Hoskyn, M., \& Lee, C. M. (1999). Interventions for Students with Learning Disabilities. New York: Guilford.

Vellutino, F., \& Scanlon, D. M. (1991). The effects of instructional bias on word identification. In I. L. Rieben \& C. A. Perfetti (Eds.), Learning to read: Basic research and its implications (pp. 189-204). Hillsdale, NJ: Lawrence Erlbaum Associates.

\section{STATEMENT OF OWNERSHIP, MANAGEMENT AND CIRCULATION}

Date of Filing: May 1, 2001 / Title of Publication: Focus on Exceptional Children Frequency of Issue: Monthly (except June, July \& August) / Location of Known Office of Publication: 9101 E. Kenyon Ave., Suite 2200, Denver, CO 80237 / Location of Headquarters of Publisher: 9101 E. Kenyon Ave., Suite 2200, Denver, CO 80237

Name and Address of Publisher, Editor, and Managing Editor: Stanley F. Love, 9101 E Kenyon Ave., Suite 2200, Denver, CO 80237

Owner: Love Publishing Company

Extent and Nature of Circulation:

$\begin{array}{cc}\text { Average No. Copies } & \begin{array}{c}\text { Single Issue } \\ \text { Each Issue During } \\ \text { Nearest } \\ \text { Freceding 12 Months } \\ 1622\end{array} \\ \text { Filing Date } \\ 1300 \\ 419 & 209 \\ 1098 & 1017 \\ 46 & 32 \\ 1563 & 1258 \\ 59 & 42 \\ 1622 & 1300 \\ 0 & 0 \\ 1622 & 1300\end{array}$

Total No. Copies Printed

Paid Circulation

Sales through Dealers, etc.

Mail Subscriptions

Other Classes Mailed

Total Paid Circulation

Free Distribution

Total Distribution

Office Use and Left Over

Total

1622

I certify that the statements made by me above are correct and complete.

(Signed) Stanley F. Love, Publisher 


\section{APPENDIX}

Intervention activities were coded based on key words and phrases (descriptions are abbreviated here). (* reflects strategy instruction activities, $* *$ reflects direct instruction activities)

Breaking down task by skills**

Children are asked to look over material prior to instruction

Children are directed to focus on material presented

Conduct probes of learning (intermittent test)**

Diagram or pictorial presentation**

Elaborate explanations*

Fading of prompts or cues

Homework

Independent practice (e.g., complete worksheet on own)

Individually paced ${ }^{* *}$

Information is provided before student discussion

Instruction is broken down into steps**

Instruction individually**

Instruction small group (2 to 5 )**

Instruction large group $(>5)$

Level of difficulty applied to each student

Mastery criteria

Modeling-from peers

Modeling of skill—from teachers**

New curriculum

Parent provides instruction

Peer provides daily feedback on student performance

Provide distributed practice (pacing), and review (weekly and monthly reviews)**

\section{Redundant text or materials}

Reminders to use certain strategies or procedures* Repeated practice (e.g., drill and repetition)

Review of material on each session

Reward and reinforcers

Short activities sequenced by teacher

Simplified demonstration

Specialized film or videotape/audiotape

Step-by-step prompts or process, multi-stepprocess directions*

Student asks questions

Task analysis

Teacher and student talk back and forth (e.g., Socratic dialogue)*

Teacher asks process-related questions*

Teacher demonstrates

Teacher (or experimenter) presents new material**

Teacher (or experimenter) provides daily feedback on student performance**

Teacher (or experimenter) states learning objectives

Teacher presents benefits of instruction

Teacher provides only necessary assistance*

Think-aloud models (modeling aloud by teacher)*

Using media (e.g., computer) for elaboration or repetition

Weekly review 


\begin{tabular}{|lc|}
\hline \multicolumn{1}{|c|}{ Author Index } & ChDEX • Volume 33 \\
\hline Barkley, Russell A. (January,2001) & Chronological Index of Titles \\
Brantlinger, Ellen (March, 2001) & School Violence and Disruption: Rhetoric, Reality, \\
and Reasonable Balance (September, 2000) \\
Drasgow, Erik (May,2001) & Integrating Services, Collaborating, and Developing \\
DuPaul, George J. (January, 2001) & Connections With Schools (October, 2000) \\
Fuchs, Douglas (February, 2001) & Standards-Based Reform and Students With \\
Fuchs, Lynn S. (February, 2001) & Disabilities: Reflections on a Decade of Change \\
Keogh, Barbara K. (December, 2000) & (November, 2000) \\
Kollins, Scott H. (January, 2001) & Risk, Families, and Schools (December, 2000) \\
Lawson, Hal A. (October, 2000) & Use and Management of Medications for Children \\
Leone, Peter E. (September, 2000) & Diagnosed With Attention Deficit Hyuperactivity \\
Malmgren, Kimber (September, 2000) & Disorder(ADHD) (January, 2001) \\
Mayer, Matthew J. (September, 2000) & Principles for Sustaining Research-Based Practice in the \\
Meisel, Sheri M. (September, 2000) & Schools: A Case Study (February, 2001) \\
Rozalski, Michael (May, 2001) & Poverty, Class, and Disability: A Historical, Social, and \\
Sailor, Wayne (October, 2000) & Political Perspective(March, 2001) \\
Schalock, Robert L. (April, 2000) & Self-Determination and Quality of Life: \\
Thurlow, Martha L. (November, 2000) & Implications for Special Education Services and \\
Wehmeyer, Michael L. (April, 2001) & Supports (April, 2001) \\
Yell, Mitchell L. (May, 2001) & Disciplining Students with Disabilities (May, 200l) \\
& \\
\hline
\end{tabular}

